\title{
MARÍA JESÚS RUBIERA Y SUS ESTUDIOS SOBRE LOS ORÍGENES DE LAS JARCHAS ROMANCES
}

\author{
Luis F. BERNABÉ PONS \\ Universidad de Alicante
}

En 1953, como preludio a unos comentarios propios en torno a la interpretación de las jarchas publicadas por Emilio García Gómez el año anterior en $A l$-Andalus ${ }^{1}$, Juan Corominas formulaba el deseo

de que en esta nueva fase de los estudios mozárabes se atienda cada vez más al testimonio de las demás lenguas romances (...) y, muy particularmente, al de las otras dos lenguas iberorromances, catalán y gallegoportugués, que en varios casos me han guiado en estas notas.

pasando después a mostrar cómo algunos términos romances de las jarchas eran, según su lectura (más tarde aceptada en algunos casos), auténticos "galleguismos"2.

No era, por supuesto, la primera ocasión en que se invocaba la presencia galaicoportuguesa a la hora de hablar de los contenidos romances recogidos en la poesía estrófica creada en al-Andalus: la muwaššạa y el zéjel ${ }^{3}$. Ya Dámaso Alonso, en su famoso estudio de 1949, había llamado la atención sobre los numerosos paralelismos

1 E. García Gómez, "Veinticuatro jarŷas romances en muwaššahas árabes", Al-Andalus, 18 (1952):57-127.

${ }^{2} \mathrm{~J}$. Corominas, "Para la interpretación de las jarŷas recién halladas (ms. G. S. Colin)", Al-Andalus, 18 (1953):140-148, 141.

${ }^{3}$ Vid. María Jesús Rubiera, Bibliografia de la Literatura Hispanoárabe, Alicante, 1988, pp. 19-36. 
temáticos ("semejanza impresionante" según Corominas) entre las jarchas recién dadas a conocer por S. M. Stern y las cantigas de amigo.

Pero, sin duda, el punto obligado de referencia en este sentido, por la preminencia temporal y por lo sólido de sus hipótesis, es la figura de Julián Ribera y Tarragó. Éste, en su discurso de ingreso en la Real Academia en 1912 acerca del cancionero de Ben Quzmān en particular y la poesía estrófica en general, se planteaba una disyuntiva para explicar la presencia románica en la poesía hispano-árabe:

o una lírica andaluza romanceada, anterior al siglo $\mathrm{X}$, más antigua que la que aparece en los Cancioneros portugueses, o una lírica gallega antiquísima, que la colonia gallega trajo a Andalucía, de donde procede la romanceada andaluza anterior a Abencuzman ${ }^{4}$.

Julián Ribera era conocedor de la existencia de la lengua románica procedente del latín vulgar que había pervivido durante siglos en la Península Ibérica (el llamado, no con exactitud, mozárabe ${ }^{5}$ ), pero se inclina, sin embargo, por la hipótesis de una lírica románica de importación: una lírica que la numerosa colonia gallega habría llevado a al-Andalus desde sus lugares de origen, una colonia gallega en la que abundaban los esclavos y esclavas de lujo, portadores de placer físico e intelectual, que habrían trasladado en sus canciones esa lírica que tendría un gran desarrollo propio posterior.

Sabido es que la hipótesis de Ribera encontró la frontal oposición de Ramón Menéndez Pidal, defensor a ultranza de una antiquísima lírica castellana con origen en la poesía hispano-árabe y, por ende, dada la fecha de creación de la muwaššạa (siglo IX), de una lírica castellana antecediendo en el tiempo a todas las líricas románicas ${ }^{6}$. De esta

${ }^{4}$ J. Ribera y Tarragó, "El Cancionero de Abencuzman", en: Disertaciones y Opúsculos, Madrid, 1928, vol. I, pp. 53-54.

5 "Es la lengua llamada mozárabe, término utilizado porque se veía que era una lengua utilizada exclusivamente por los cristianos que vivían entre los musulmanes de la Península Ibérica, aunque en realidad era una lengua usada también por los musulmanes de origen hispánico -muladíes- y por los judíos", María Jesús Rubiera, Literatura Hispanoárabe, Madrid, 1992, p. 154.

${ }^{6}$ Vid. R. Menéndez Pidal, Poesía árabe y poesía europea, Madrid, 1941, pp. 70-71; Id., Estudios Literarios, Madrid, 1957, pp. 199-269. 
manera, la lírica romance presente en al-Andalus era toda autóctona y su lengua, la romance de al-Andalus: el mozárabe, de naturaleza iberoromance. Tras el descubrimiento de las jarchas y sus primeros intentos de lectura, Menéndez Pidal seguirá sosteniendo siempre su postura "castellanista", enemiga de cualquier rastro extra-mozárabe en la lírica romance de al-Andalus?

Bajo el inmenso manto de la autoridad de Pidal las teorías de Ribera quedaron oscurecidas en un segundo plano en favor de una primitiva lírica castellana expresada en mozárabe, haz dialectal no bien conocido sobre el que habia que interpretar todas las jarchas existentes. En este contexto, Rafael Lapesa publicó en 1960 un trabajo ${ }^{8}$ que abría de forma evidente posibilidades nuevas de lectura para las jarchas, y sus aportaciones fueron recogidas por García Gómez con el significativo título de ¿Nuevos horizontes?; también significativamente, el trabajo de Lapesa y su mención pasaron desapercibidos.

$Y$ es que el trabajo de Rafael Lapesa hacía un descubrimiento inaudito: en las jarchas existran de forma clara galicismos y provenzalismos, lo cual, unido a los galleguismos que había detectado Corominas, ofrecía un panorama de las jarchas muy distinto a lo hasta ahora contemplado. Porque el interrogante surge de inmediato: ¿cómo pueden aparecer elementos galorrománicos dentro de una lengua de naturaleza iberorrománica como el mozárabe? ${ }^{10}$

7 "...el centro de la Península, esto es, Castilla ofrece los primeros textos líricos existentes, siglo y medio anteriores a los portugueses conocidos.", "La primitiva lírica europea. Estado actual del problema", Boletín de la Real Academia Española, 31 (1951):187-270.

8 "Sobre el texto y lenguaje de algunas jarchas romances", Boletín de la Real Academia Española, 40 (1960):53-65.

${ }^{9}$ La jarchas romances de la serie árabe en su marco, Madrid, 1965, pp. 2829. Vid. ya en 1956, "La lírica hispano-árabe y la aparición de la lírica románica", Al-Andalus, 21 (1956):311.

10 " ¿Cómo explicar la existencia de elementos extraños al iberorrománico? Aun suponiendo que los visigodos por su permanencia en el sur de Francia hubiesen introducido elementos galos en su latín vulgar ipor qué esos elementos no se encuentran en el asturleonés descendiente del habla cortesana del Toledo visigodo?", María Jesús Rubiera, "Una nueva hipótesis sobre la lengua de las jarchas a partir de las investigaciones de Rafael Lapesa", Homenaje al Profesor 
Éste y otros interrogantes son los que se planteó la doctora María Jesús Rubiera en 1987 cuando aborda, desde una perspectiva multidisciplinar constante en su actividad investigadora, el problema de las jarchas, y la primera cosa en la que hace hincapié es que esos "Nuevos horizontes" sólo pueden ser comprendidos cabalmente haciendo un "Viaje de regreso a las teoŕas de Julián Ribera".

El arabista valenciano había estudiado la documentación que hacía referencia a la colonia extranjera en al-Andalus, especialmente la referida a la compra de esclavas de lujo. En elia aparecían frecuentemente, en efecto, las esclavas gallegas, pero también, como señala la profesora Rubiera, los esclavos ifrany, es decir, "francos", pero también procedentes de Cataluña y especialmente de Languedoc". Si Ribera hablaba de que esos esclavos saqaliba gallegos fueron los introductores de la lírica románica en al-Ándalus, por idénticas razones históricosociologicas (presencia de esclavas de lujo, instruidas en las artes, lírica autóctona con un gran desarrollo posterior...) afirma la doctora Rubiera que puede sostenerse lo mismo para las esclavas "francas". Éstas cantarían perfectamente canciones en árabe, pero también podrían recordar las canciones oídas en su infancia y cantarlas a sus amos.

Asi, pues, existe un contexto histórico y sociológico en el que se puede aducir sólidamente la existencia de una lírica extra-peninsular en la poesía estrófica andalusí y que daría razón a esos términos leídos por Lapesa. Pero el paso adelante definitivo habría de ser la lectura completa de una jarcha en lengua occitana; y éste es el que dio María Jesús Rubiera en su trabajo publicado en Al-Qantara, ofreciendo resultados espectaculares con la nueva lectura de la jarcha número 3 de la numeración de García Gómez ${ }^{12}$.

Esta jarcha, en la lectura definitiva de García Gómez

Lapesa, Murcia, 1990, p. 230.

11 María Jesús Rubiera, "Relacions d'anada i tornada entre la poesia provençal i la poesia àrab a través dels catalans: kharges en llengua occitana", Actes del Vuitè Col.loqui Internacional de Llengua i Literatura Catalanes, Montserrat, 1989, vol. I, p. 241.

12 "Veinticuatro jarŷas...", pp. 78-79; Las jarchas..., pp. 66-67; "Las jarchas", El comentario de textos. 4. La poesía medieval, Madrid, 1984, p. 413. 
Ya fätin $A$ fätin

Oš y enträ

kand' o yilos keded
¡Oh seductor, oh seductor!

Entráos aqut

cuando el gilos duerma

ya ofrecía dos elementos propios del occitano, a saber, el adverbio $y$ más el término clave -y claramente provenzal- giloss ${ }^{13}$. A esto hay que añadir la impresionante semejanza con el refrain provenzal hallado por Armistead $^{14}$

Quant lo jilós er fora

bel ami

vene vos a mi.

La profesora Rubiera ofrece su propia lectura de la jarcha en occitano -que resulta requerir menos alteraciones del texto árabe del manuscrito que las lecturas anteriores- con el transparente resultado de

Vos i entratz

Cand er jilós feritz
Entraos aqui

cuando gelós sea herido ${ }^{15}$

con significado completo y coincidiendo con la moaxaja en rima (-id/itz) y argumento (queja de la muchacha porque su amante va a la guerra y la deja sola).

Además de ésta, completamente en provenzal, la profesora Rubiera Mata investiga otros provenzalismos en distintas jarchas, provenzalismos que, como gilos, no significaban simplemente préstamos lingüisti-

${ }^{13}$ El término aparece en tres ocasiones en el corpus editado y estudiado por García Gómez (jarchas III, XXVII y XXXI) sucesivamente con las formas ýelóš ŷelós - hilóš. Vid. explicación y otras referencias del término en la España medieval en Las jarchas..., pp. 347-348. Vid. María Jesús Rubiera, "Cançonetes de tipus 'kharja' en la literatura catalana", en: A. Ferrando - A. Hauf (eds.), Miscel lània Joan Fuster. Estudis de Llengua i Literatura, Barcelona, 1989, vol. I, p. 4

14 "A mozarabic Harğa and a Provençal Refrain", Hispanic Review, 41 (1973):416-417.

${ }^{15}$ Literatura Hispanoárabe, p. 157; "La lengua romance...", 327-328. 
cos galorrománicos sino que "podrían servir de 'palabras-clave' si tenían una tradición literaria"16. Así, en una jarcha de la serie hebrea $^{17}$, aparte de los galorromanismos cor y vol, aparece la palabra segur, con tradición en la poesía catalana, mientras que en otra jarcha, repetida en dos moaxajas de distintos autores ${ }^{18}$, aparece la fórmula elocutiva a lessa, frecuente en la poesía provenzal ${ }^{19}$.

De esta manera, queda documentada en las jarchas no sólo la existencia de una serie de términos románicos, sino la existencia de una lírica ultrapirenaica en al-Andalus anterior a la poesía de los trovadores. Y como tales préstamos o trasvases literarios, Marfa Jesús Rubiera hace hincapié en el hecho de que "el fenómeno de su importación habrá que buscarlo en los círculos literarios a los que tuviesen acceso los noárabes y se ha de encontrar, sin duda, en el ambiente de los esclavos músico-cantores donde los șaqăliba o esclavos de origen europeo tenían un protagonismo indudable y documentado desde antiguo y en donde hay que situar la creación de la poesía estrófica" ${ }^{20}$.

Una vez establecido el factum de la plausible lectura de ciertas jarchas en lengua occitana, la profesora Rubiera delinea entonces su hipótesis a través de tres líneas de investigación simultáneas, pero que van resultando convergentes en su desarrollo hasta confluir en el vértice de una poesía estrófica andalusí que recoge y glosa una lírica femenina no-árabe, peninsular y extra-peninsular, llevada a al-Andalus por la multilingüe colonia de los esclavos șaqăliba.

En primer lugar, se vuelve en torno a la propia historia de la muwašsaha, retomando los textos árabes medievales que hablan sobre

${ }^{16}$ Literatura Hispanoárabe, p. 158. Vid. J. T. Monroe, "Formulaic diction and the common origins of Romance lyric traditions", Hispanic Review, 43 (1975):341-360.

17 J. M. Solá Solé, Corpus de poesía mozárabe, Barcelona, 1987, pp. 327 329 (n' VII).

${ }^{18}$ García Gómez, Las jarchas..., XXX a,b; J. M. Solá Solé, Corpus..., pp. 89-90.

19 Vid. María Jesús Rubiera, "Presencia románica extra-andalusí en las jarchas", Poesia Estrófica. Actas del Primer Congreso Internacional sobre Poesia Estrófica Arabe y Hebrea y sus Paralelos Romances, Madrid, 1991, pp. 290-292.

${ }^{20}$ Ibid., pp. 292-293. 
esta forma poética andalusf y volviendo a valorar las informaciones que ellos nos proporcionan, así como los múltiples estudios acerca del nacimiento y desarrollo de esta original creación andalusi. Seguin las noticias en ellos expuestas Muhammad ibn Maḥmūd, el ciego de Cabra, sobre una cancioncilla en árabe vulgar o en lengua no árabe compuso un poema de versos cortos en árabe clásico, colocando la cancioncilla al final como salida (jarya) de la moaxaja y rimando con ella los versos en árabe clásico, utilizando "metros descuidados e inusuales" respecto a los de la métrica clásica de Jalîl.

Es decir, como señala la profesora Rubiera, unos metros que resultaban inauditos porque su origen y pauta era un poema en árabe vulgar o en una lengua románica, ambas de métrica acentual y sílabas contadas y no de métrica cuantitativa como el árabe clásico. La moaxaja así correspondería "a una métrica silabicoacentual bajo cuya pauta se ha podido medir la poesía estrófica sin contradicciones importantes" ${ }^{21}$.

Hay, con todo, una importante salvedad que realiza María Jesús Rubiera al hilo del conocido texto de Ibn Bassām en su Dajtra: el poema inventado por el Ciego de Cabra no era todavía estrófico, no tenía mudanzas, sino que era aún un poema monorrimo creado a partir de la jarcha. La muwašsaha como tal, como un collar o cinturón con dos tipos de cuenta, no aparecerá hasta principios del siglo XI, con Ubāda Ibn Mā' al-Samā', que será quien idee el entrelazamiento en las estrofas ${ }^{22}$.

Los poetas moaxajeros, entonces, toman una cancioncilla preexistente y la glosan en árabe clásico según una forma poética inusitada en la literatura árabe. ¿Cómo estaba formado ese venero lírico que alimentará al nuevo género? Ya existía, al menos desde principios del siglo $\mathrm{X}$, un abundante corpus de poemas en árabe vulgar a disposición de los poetas, pero, razona la profesora Rubiera, no puede afirmarse lo

${ }^{21}$ Literatura Hispanoárabe, p. 153; vid. E. García Gómez, "Métrica de la moaxaja y métrica española", Al-Andalus, 39 (1974):1-259.

22 Vid. los textos de Ibn Bassäm y sus comentarios en Literatura Hispanoárabe, pp. 152-153. La moaxaja, entonces, nació monorrima, por lo que, como señala la profesora Rubiera, hay que abandonar la idea de que esos poemillas finales que forman las jarchas dieran una posible forma estrófica a los poemas que los glosaban ("La lengua romance...", pp. 322-323). 
mismo para los poemas en lengua mozárabe "porque esta posible lírica fue tan débil que no fue capaz de sobrevivir a sí misma, a pesar de la emigración de cristianos y judíos a los reinos del Norte" 23 . No quiere esto decir, por supuesto, que los poetas andalusfes carecieran por completo de ellos ${ }^{24}$, sino que, en primer lugar su número es muchísimo menor $y$, en segundo lugar, si se recogieron poemas de una lírica de débil entidad, pudieron perfectamente haber sido tomados otros textos poéticos procedentes de unas líricas que presagiaban un importante desarrollo posterior.

$Y$ todos los datos valorados apuntan, tanto desde el punto de vista del poeta moaxajero como desde el de la transmisión de esa lírica románica, a un medio determinado que, como queda dicho, había sido apuntado por Julián Ribera y que queda ahora aquilatado por las investigaciones de María Jesús Rubiera: el medio de los esclavos músico-cantores, con un protagonismo muy documentado de los esclavos de origen europeo.

Conocido es cómo algunas de las esclavas saqãliba eran educadas para ser una especie de hetairas o "esclavas de lujo", siendo adiestradas en los más variados campos del saber, con especial incidencia en la música y la poesía, llegando a alcanzar algunas de ellas una gran maestria como esclavas cantoras o qiya ${ }^{25}$. Como señala la profesora Rubiera, es perfectamente posible que en algún momento estas esclavas también entonaran ante sus amos las canciones en lengua vernácula ớdas en su infancia.

Sólo eran necesarios unos oídos sensibles para escuchar, y estos ordos interesados no faltaban en los círculos literarios andalusíes. Emilio García Gómez ya había dado a conocer un texto que "si servía para la invención del zéjel, podría haber sido el procedimiento de la invención de la moaxaja"26. según el texto, Ibn Bay̧ya se encerró durante años

23 "La lengua romance...", p. 322.

24 Vid. el texto de al-Tifāš̀ en E. García Gómez, Poesía Arabigoandaluza, Madrid, 1952, pp. 30-31.

25 Vid. Ch. Pellat, "Les esclaves-chanteuses de Ğăhịị", Arabica, 10 (1963): 120-147.

${ }^{26}$ María Jesús Rubiera, "La lengua romance..." ", p. 324. 
con esclavas cantoras hasta conseguir reunir el canto cristiano con el $a_{\text {rabe }}^{27}$. Es decir, una vez más, es en el medio de los esclavos cantores donde se dan las condiciones precisas para poder intentar trasvases y combinaciones de este tipo.

Pero es que esta actividad consciente casi de alquimia musical y lírica ya se daba en al-Andalus mucho tiempo antes de Ibn Baŷya (m. 1136). Así lo ha demostrado la profesora Rubiera Mata con su descubrimiento de un texto que prueba de forma palmaria la presencia de la lírica europea en al-Andalus ${ }^{28}$. El egipcio Ibn Faḍl Allāh al${ }^{c}$ Umarī (m. 1349) en su Masalik al-absär ofrece en la parte dedicada a la música las biografías de diversos cantores y cantoras. Entre ellas aparece la de un cantor llamado Salīm, liberto del príncipe al-Mugīra, hijo del emir al-Hakam I (796-822), que había sido encargado de atender a unos embajadores cristianos que habian llegado a la corte de Cordoba.

El antiguo esclavo hizo retrasar la partida de la embajada cristiana hasta que aprendió de ella el arte de la música, y cuando hubieron marchado, Salīm se dedicó a combinar lo aprendido con el canto de una diestra esclava iraqur del harén de al-Mugira. A comienzos del siglo IX, pues, se intentan combinar los cantos cristianos y los árabes en alAndalus. Pero todavía suministra la profesora Rubiera un precioso dato más: la noticia se desarrolla en vida del emir al-Ḥakam, y la única embajada cristiana que llegó a Córdoba en este período fue la de los enviados de Carlomagno en el año 807.

Así, Salìm (¿él mismo de origen ifrany y por eso encargado de acoger a sus compatriotas?) aprendió de los cristianos el arte de la música. Pero, se cuestiona la profesora Rubiera, ¿qué clase de música fue la aprendida? Difícilmente la de la reforma carolingia, y propone, por el contrario, que "habria que pensar en las winileodas o canciones

${ }^{27}$ Emilio García Gómez, "Una extraordinaria página de Tífās̄i y una hipótesis sobre el inventor del zéjel", Études d'Orientalisme dédiées à la mémoire de $E$. Lévi-Provençal, Paris, 1962, pp. 519-520.

28 "Presencia románica...", pp. 293-294; Literatura Hispanoárabe, pp. 159. 160 . 
de amigo que en el año 789 Carlomagno prohibió componer y difundir a las monjas de las abadías" ${ }^{12}$.

Es decir, que en una fecha tempranísima llegaron a al-Andalus unas influencias líricas ultrapirenaicas dentro del medio de los esclavos profesionales de la música y la canción (y la profesora Rubiera recuerda, con J. T. Monroe, que la muwaššha fue siempre un poema musical, un poema cantado), uno de los cuales inició una aventura que sólo acertaría a culminar, tres cuartos de siglo más tarde, el Ciego de Cabra.

Por fin, la tercera de esas líneas convergentes de investigación que Marfa Jesús Rubiera explora se refiere a la propia naturaleza de esas cancioncillas sobre las cuales los moaxajeros yerguen sus glosas poéticas en árabe: "Las jarchas románicas, así como parte de las que se encuentran en árabe dialectal son canciones eróticas en labios femeninos, 'canciones de amigo' o Frauenlieder (...). Estas canciones no están puestas en labios femeninos por una convención, sino que muestran un erotismo visto desde el punto de vista femenino" ${ }^{30}$. Esto es, la poesía marginal femenina conocida en la Edad Media en la que la mujer expresa sin filtro alguno su deseo amoroso, una poesía de remotos orígenes griegos (relacionados a su vez con el culto mesopotámico a Astarté) en cuya lírica arcaica se han hallado fragmentos de sorprendente paralelismo con las jarchas. A través de unos desarrollos paralelos en diversos lugares, se conformó una serie de ramas desde ese tronco común, una de las cuales ocuparía de forma homogénea la Romania y de la que las jarchas sería la más temprana manifestación recogida por escrito $^{31}$. Esta manifestación recogería una serie de "Formulas Elocuti-

29 "Presencia románica...", p. 293. Vid. G. E. von Grunebaum, "Lírica románica' before the Arab Conquest", Al-Andalus, XXI, 2 (1956):405; P. Dronke, Medieval Latin and the Rise of European Love Lyric, Oxford, 1968 ${ }^{2}$, vol. I, pp. 27-28.

30 "Una nueva hipótesis...", p. 231.

${ }^{31}$ María Jesús Rubiera, Poesía Femenina Hispanoárabe, Madrid, 1990, pp. 20-29; Id. "La voz de las poetisas en al-Andalus y la problemática de la voz femenina literaria medieval ${ }^{\mathrm{n}}, \mathrm{La}$ voz del silencio. I: Fuentes directas para la historia de las mujeres (siglos VIII-XVII), Madrid, 1992, pp. 65-70. 
vas" propias de esta lírica que se han conservado de forma tradicio$\mathrm{nal}^{32}$.

Es, argumenta la profesora Rubiera, la poesía hispanoárabe de la moaxaja la primera literatura medieval en recoger este tipo de poesía porque con frecuencia, como género poético que recoge la temática árabe clásica, tiene como tema el sentimiento erótico hacia un efebo y "la expresión del deseo femenino cuadra perfectamente con la temática homosexual del poema árabe ${ }^{133}$, por lo que entran en la literatura árabe, como quería su tratadista egipcio Ibn Sană $\bar{c}^{c} \bar{a}$ al-Mulk, en el género muyün: descarado, desvergonzado ${ }^{34}$.

$Y$ desde estos razonamientos literarios alcanza la profesora Rubiera un nuevo argumento en desfavor de la idea de que la voz femenina presente en las jarchas sea la de las doncellas mozárabes: si a las jóvenes musulmanas no les era dado frecuentar mucho los ambientes literarios de los poetas árabes, mucho menos a las mujeres cristianas "cuando seguramente ni su voz ni su rostro pudo ser visto por ningún árabe, guardadas por sus familias cristianas de las miradas de los hombres y mucho más de los varones musulmanes"35. Las únicas mujeres con acceso a este ámbito literario árabe $\mathrm{y}$, a la vez, con una formación y una memoria lírica prestas a ser puestas en práctica eran, de nuevo, las qiyan, las esclavas-cantoras.

Una vez establecido el origen y naturaleza de esos poemillas, echa de menos la profesora Rubiera dentro de los estudios sobre las jarchas andalusíes una aproximación de índole literaria hacia esos textos encuadrados en las muwašsahas. Así, teniendo en cuenta todos los datos anteriores referentes a las distintas procedencias de las jarchas conservadas, esboza una primera y provisional tipología temática de las jarchas,

${ }^{32} \mathrm{Y}$ no solamente en el corpus de las jarchas: vid. los hallazgos hechos por la profesora Rubiera Mata de "Fórmulas elocutivas" como las de las jarchas en la literatura catalana en "Cançonetes de tipus..." , pp. 6-8; "Una fórmula elocutiva en la lírica tradicional romànica i una altra possible khartja occitana", $A$ Sol Post. Estudis de Llengua i Literatura, Alcoi, 1 (1990):193-196.

${ }^{33}$ Literatura Hispanoárabe, p. 163.

34 María Jesús Rubiera, "Una nueva aproximación al estudio literario de las jarchas andalusíes", Sharq Al-Andalus. Estudios Árabes, 5 (1988):89-100.

${ }^{35}$ Literatura Hispanoárabe, p. 155; vid. Poesía Femenina..., pp. 23-24. 
tanto de las que se encuentran en árabe vulgar como de las importadas de las líricas románicas peninsulares y extrapeninsulares. Son analizadas sus propias características literarias y relacionadas temática y técnicamente con sus posibles lugares de origen e importación, explicando a través de un esquema de evolución histórica cómo va desapareciendo el uso de la poesía tradicional femenina románica y los poetas se ven obligados a acudir cada vez más a su propia inventiva para componer jarchas ya fuera del ámbito de la lírica de importación ${ }^{36}$.

Una lírica, pues, de carácter femenino, común al dominio románico y conservada durante siglos de forma tradicional, es la que los poetas moaxajeros andalusíes recogieron para crear un nuevo tipo de poema: un poema en árabe clásico que se ajustara en métrica y rima a esa última vuelta que, a la vez, abría y cerraba la muwašsạ̧a. Y una lírica que recogía una expresión poética en árabe vulgar pero también en lenguas románicas: el mozárabe, menos representado de lo que se ha supuesto, y también lenguas como el occitano o el gallego-portugués. No pretendían los poetas moaxajeros, como ha afirmado múltiples veces la profesora Rubiera, hacer una "antología de la poesía mozárabe", sino que recogían las cancioncillas románicas, viniesen de donde viniesen, para medir su calidad de literatos con el nuevo artificio poético. En este sentido, la realidad multilingǘstica de al-Andalus queda perfectamente dibujada con esas esclavas-cantoras de variado origen europeo, que serían la fuente accesible para los poetas.

Una realidad literaria de base plurilingüe es la que queda afirmada en las jarchas en las investigaciones, también plurales en sus perspectivas de acercamiento, de Marfa Jesús Rubiera, una realidad que recoge los textos poéticos populares más antiguos que se conservan de la lírica de las lenguas romances en el momento de la "primavera temprana", ahora con toda la razón, "de la lírica europea". Unos nuevos horizontes que ya son hollados.

36 "Una nueva aproximación...", pp. 94-100; Literatura Hispanoárabe, pp. $160-163$. 